\title{
ANALISIS KEMAMPUAN BERPIKIR KRITIS MAHASISWA PENDIDIKAN FISIKA TENTANG TEKNOLOGI PEMANFAATAN SINAR ULTRAVIOLET PADA BIDANG KESEHATAN
}

\author{
Azurulia Maurilla Syifa ${ }^{1}$, Sudarti ${ }^{2}$ \\ azuruliasyifa@gmail.com \\ ${ }^{1,2}$ Pendidikan Fisika Universitas Jember, Kabupaten Jember, Jawa Timur, İndonesıa
}

Received: 25 Maret 2021

Revised: 5 April 2021

Accepted: 12 Desember 2021

\begin{abstract}
This study aims to determine the critical thinking ability of physics education students in understanding the use of ultraviolet light in the health sector. The research method used in this research is using a qualitative descriptive method. The research subjects used are physics education students in semester 5 , totaling 42 people. The data collection technique was using a reasoned questionnaire written test. The critical thinking indicators that are measured are identifying, providing further explanation, concluding, and determining strategies and tactics. From the research data then analyzed to determine the presentation. From the results of the data analysis, it can be concluded that the critical thinking ability of physics education students is still around $32.6 \%$, and is still fairly poor in solving problems regarding technology for the use of ultraviolet light in the health sector.
\end{abstract}

\begin{abstract}
Abstrak: Penelitian ini bertujuan untuk mengetahui kemampuan berpikir kritis mahasiswa pendidikan fisika dalam memahami pemanfaatan sinar ultraviolet di bidang kesehatan. Metode penelitian yang digunakan dalam penelitian ini yaitu menggunakan metode deskriptif kualitatif . Subjek Penelitian yang digunakan yaitu mahasiswa pendidikan fisika semester 5 yang berjumlah 42 orang. Teknik pengumpulan data yaitu menggunakan tes tulis kuesioner beralasan. Indikator berpikir kritis yang diukur yaitu mengidentifikasi, memberikan penjelasan lanjut, mwnyimpulkan, dan menentukan strategi dan taktik. Dari data hasil penelitian kemudian dianalisi untuk menentukan presentasis. Dari hasil analisis data kesimpulannya kemampuan berpikir kritis mahasiswa pendidikan fisika masih sekitar 32,6\%, dan masih terbilang kurang baik dalam menyelesaikan masalah tentang teknologi pemanfaatan sinar ultraviolet pada bidang kesehatan.
\end{abstract}

Kata kunci: deskriptif kualitatif, berpikir kritis, kesehatan, sinar ultraviolet, teknologi

\section{PENDAHULUAN}

Negara indonesia saat ini berkembang sangat baik dan pesat. Banyak cara untuk memajukan bangsa indonesia dari berbagai sektor. Salah satunya dari sektor pendidikan. Pendidikan merupakan hal yang sangat penting karena dengan adanya pendidikan akan menghasilkan output atau tenaga-tenaga yang berkualitas dan dapat memajukan bangsa indonesia. Oleh karena itu pemerintah Indonesia selalu berupaya meningkatkan mutu pendidikan di Indonesia (Harefa, D. P., \& Gumay, O. P. U, 2021). Perguruan tinggi mempunyai tantangan untuk menghasilkan sumber daya manusia yang berkualitas. Kegiatan perkuliahan diharapkan mampu menumbuhkan dan mengembangkan kemampuan hard skill 
dan soft skill mahasiswa (Zakiya, Z., Amin, A., \& Lovisia, E, 2019). Kenyataan di lapangan, mahasiswa hanya memiliki kemampuan hard skill dimana mahasiswa hanya diberikan materi, teori, rumus. Berpikir kritis merupakan salah satu indikator dari soft skill belum dimiliki mahasiswa. Sejalan dengan Farkhiyah (2014) salah satu yang termasuk soft skill berupa kemampuan berpikir kritis dan kemampuan dalam pemecahan masalah.

Di era sekarang yang semakin berkembang ini keterampilan berpikir kritis merupakan kemampuan yang sangat diperlukan bagi seorang mahasiswa. Pengertian dari kemampuan berpikir kritis itu sendiri adalah kemampuan yang digunakan untuk memecahkan masalah, mengambil keputusan, membujuk, menganalisis, dan melakukan penelitian. Kemampuan berpikir merupakan salah satu hal yang berperan penting dalam kegiatan belajar mengajar, diharapkan dengan memiliki kemampuan berpikir kritis mahasiswa mampu memahami materi yang dipelajari dan dapat menyimpulkan, berwawasan luas.

Kemampuan berpikir kritis diperlukan dalam membuat keputusan untuk melakukan atau mempercayai suatu hal yang diawali dengan berpikir dengan beralasan dan berpikir reflektif (Ennis, 2013; Fascione, 2000). Berpikir kritis bertujuan untuk memberikan kepercayaan atau tidak pada klaim yang diberikan. Berpikir kritis berkaitan erat dengan Matematika, khususnya dalam menyelesaikan permasalahan. Namun pada kenyataannya, para lulusan tidak memiliki kompetensi yang cukup dalam mata pelajaran dan menunjukkan kelemahan dalam berpikir kritis, manajemen waktu, dan kapasitas untuk bekerja mandiri serta etika dalam bekerja (Al-Kindi \& Al-Mekhlafi, 2017). Oleh karena itu, berpikir kritis perlu didorong dan diperkuat pada semua jenjang pendidikan (Walker, 2003).

Dalam berpikir kritis ada aspek aspek yang mendukung agar mahasiswa dapat berpikir kritis sehingga hasilnya nanti setelah mempelajari materi mahasiswa bukan hanya dapat mengerti dan memahami saja tetapi juga dapat menyimpulkan apa yang telah didapatkannya. Jenis penelitian dan pengembangan tes untuk mengetahui kemampuan berpikir kritis mahasiswa sebelumnya pernah dilakukan oleh Ennis(1987), kali ini akan dilakukan tes yang sama dengan mengacu pada aspek berpikir kritis pada mahasiswa pendidikan fisika. Sebagai calon guru, mahasiswa pendidikan fisika harus menguasasi materi fisika di sekolah. Salah satu mata pelajaran yang diajarkan dalam pendidikan formal di sekolah adalah Fisika. Fisika merupakan ilmu yang mempelajari tentang fenomena gejala alam dan tak lepas dari penerapan kehidupan sehari-hari. Fisika juga merupakan ilmu universal yang mendasari perkembangan teknologi modern dan mempunyai peran penting dalam berbagai disiplin ilmu dan mengembangkan daya pikir manusia. Untuk menguasai dan meciptakan teknologi dimasa 
depan diperlukan penguasaan konsep-konsep Fisika sejak dini dan dilakukan suatu tindakan yang terencana. Oleh karena itu, Fisika berperan mempersiapkan siswa atau generasi penerus agar dapat menghadapi tantangan-tantangan di kehidupan yang semakin berkembang dan modern. Persiapan-persiapan yang tersebut dilakukan dengan membekali siswa kemampuan berpikir logis, mengembangkan, pemahaman konsep, sistematis, mandiri, dan kreatif (Ariani, T., \& Yolanda, Y, 2019).

Berpikir krtitis terdiri dari kemampuan kognitif adan disposisi. Disposisi dapat dilihat sebagai sikap, kebiasaan, keingintahuan, fleksibilitas, kecenderungan untuk mencari alasan, keinginan dan kemauan untuk mencari sudut pandang yang beragam (Lai, 2011). Pada penelitian ini, analisis dilakukan terhadap kemampuan berpikir kritis mahasiswa saja. Berdasarkan pengertian dan komponen berpikir kritis, indikator berpikir kritis yang digunakan pada penelitian ini yaitu keterampilan mengidentifikasi, Memberikan penjelasan lanjut, menyimpulkan, dan keterampilan strategi dan taktik dalam pembelajaran.

Pada era globalisasi seperti sekarang ini banyak sekali teknologi terbagu yang mampu bersaing di era global. Kecanggihan dari teknologi ini tidak jauh dari pemanfaatan gelombang elektromagnetik. Gelombang elektromagnetik adalah gelomabang yang memancar tanpa media rambat yang membawa muatan energi listrik dan magnet (elektromagnetik). Tidak seperi gelombang pada umumnya yang membutuhkan media rambat , gelombang elektromagnetik tidak membutuhkan media rambat (Salsabillah, S., Sudarti., \& Supeno, 2018). Salah satu materi yang dianggap kurang begitu penting yaitu gelombang eletromagnetik lebih tepatnya pada salah satu spektrum gelombang elektromagnetik yaitu sinar ultraviolet, bagaimana manfaatnya dan penerapannya di bidang kesehatan. Sehingga dengan diadakannya penelitian ini kita dapat mengetahui kemampuan analisis berpikir kritis mahasiswa dalam memahami pemanfaatan teknologi terkini oleh sinar ultraviolet dalam bidang kesehatan.

\section{METODE PENELITIAN}

Metode penelitian yang digunakan dalam penelitian ini yaitu metode deskriptif kualitatif, fokus analisis ini adalah melihat bagaimana kemampuan berpikir kritis mahasiswa terhadap pemanfaatan sinar ultraviolet dalam bidang kesehatan. Subyek penelitian yaitu mahasiswa pendidikan fisika semester 5 sebanyak 42 mahasiswa, teknik pengumpulan data yaitu dengan memberikan kuesioner berupa soal soal mengenai pemanfaatan sinar ultraviolet dalam bidang kesehatan. Tipe soal yang digunakan yaitu checkbox, tujuannya dengan dibuat seperti ini 
mahasiswa dapat memilih jawaban mana yang menurut mereka paling benar dan dituntut teliti dalam menjawabnya.

Tes tulis terdiri dari 6 butir soal dengan mengacu pada indikator kemampuan berpikir kritis yang diambil.

Tabel 1. Indikator kemampuan berpikir kritis

\begin{tabular}{|c|c|c|c|}
\hline No. & $\begin{array}{c}\text { Aspek Berpikir } \\
\text { Kritis }\end{array}$ & Indikator & $\begin{array}{c}\text { Nomor } \\
\text { soal }\end{array}$ \\
\hline 1. & Mengidentifikasi & $\begin{array}{l}\text { mengidentifikasi hal yang benar mengenai sinar ultraviolet } \\
\text { mengidentifikasi dampak apa saja yang terjadi bila terkena } \\
\text { sinar ultraviolet berlebihan } \\
\text { mengidentifikasi hal yang benar mengenai manfaat sinar } \\
\text { ultraviolet dalam kesehatan }\end{array}$ & 1,4 dan 5 \\
\hline 2. & $\begin{array}{c}\text { Memberikan } \\
\text { penjelasan lanjut }\end{array}$ & menjelaskan lebih lanjut mengenai jenis sinar ultraviolet & 2 \\
\hline 3. & Menyimpulkan & menganalisis tindakan untuk menghindari dampak & 3 \\
\hline 4. & $\begin{array}{l}\text { Strategi dan } \\
\text { taktik }\end{array}$ & Menganalisis bagaimana urutan proses sterilisasi ruangan & 6 \\
\hline
\end{tabular}

(Pradana, S. D. S., Parno, P., \& Handayanto, S. K, 2017)

Kriteria pengklasifikasian tingkat kemampuan berpikir kritis dilihat dengan cara membandingkan skor hasil tes mahasiswa pendidikan fisika dengan skor jumlah total bila menjawab dengan benar.

Tabel 2. Klasifikasi kemampuan berpikir kritis

\begin{tabular}{cc}
\hline Presentase $(\%)$ & Kategori \\
\hline $0-25$ & Sangat Kurang \\
$26-50$ & Kurang baik \\
$51-75$ & Cukup baik \\
$76-100$ & Baik
\end{tabular}

Cara membandingkan hasil tes dengan pengklasifikasian kemampuan berpikir kritis. Maka, menggunakan presentase kemampuan berpikir kritis tiap mahasiswa, Persamaan (1) yaitu:

$$
X=\frac{a}{b} \times 100 \%
$$

Keterangan:

$\mathrm{X}=$ Presentase kemampuan berpikir kritis

$\mathrm{a}=$ Jumlah nilai yang benar per mahasiswa

Puplished at https://ojs.stkippgri-lubuklinggau.ac.id/index.php/SJPIF 
$\mathrm{b}=$ Jumlah keseluruhan nilai mahasiswa

\section{HASIL DAN PEMBAHASAN}

Kemampuan berpikir kritis dapat ditentukan dengan menganalisis hasil data kuesioner. Kali ini menganalisis kemampuan berpikir kritis mahasiswa pendidikan fisika, berikut ini merupakan hasil analisis gambaran setiap soal berdasarkan aspek berpikir kritis yang dijawab benar oleh mahasiswa pendidikan fisika. Mari kita bahas satu persatu soal dari berbagai aspek berpikir kritis yang diambil, untuk soal yang pertama mengacu pada aspek identifikasi,

Pada soal nomor satu jawaban benar terdapat pada pilihan A, B, dan D. Terlihat pada grafik batang mahasiswa yang menjawab benar dari pilihan tersebut terlihat banyak, 36 orang memilih A, 23 orang memilih B, dan 14 orang memilih D karena ini merupakan soal identifikasi jadi mahasiswa yang hanya menjawab benar ketiganya yaitu berjumlah 8 orang dari keseluruhan 43 orang.

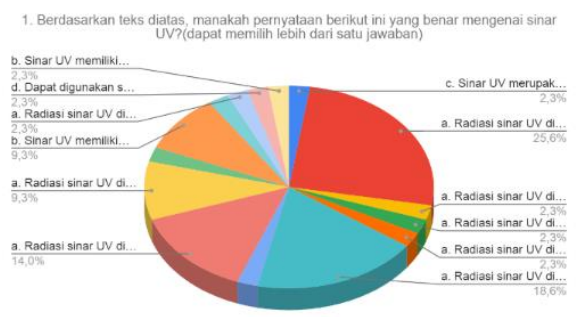

Gambar 1. Persebaran jawaban soal pertama.

Pada soal nomor dua jawaban benar terdapat pada pilihan C. Terlihat pada grafik batang mahasiswa yang menjawab benar dari pilihan tersebut terlihat banyak, 19 orang memilih $\mathrm{C}$. Soal ini menganalisis kemudian mahasiswa diharuskan untuk memberikan alasan kenapa mereka menjawab pilihan tersebut. Mahasiswa yang menjawab benar yaitu berjumlah 11 orang dari keseluruhan 43 orang.

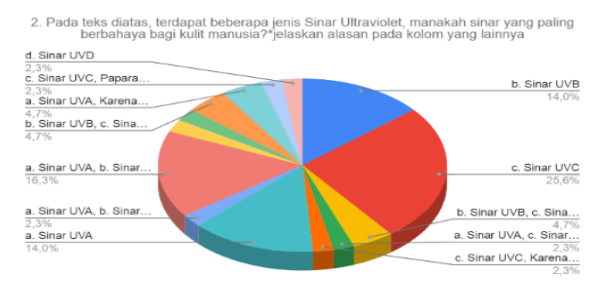

Gambar 2. Persebaran jawaban soal kedua.

Pada soal nomor tiga jawaban benar terdapat pada pilihan B, dan C. Terlihat pada grafik batang mahasiswa yang menjawab benar dari pilihan tersebut terlihat banyak, 30 orang Puplished at https://ojs.stkippgri-lubuklinggau.ac.id/index.php/SJPIF 
memilih B, dan 29 orang memilih C. Kemudian, soal ini merupakan soal analisis dan mahasiswa diharuskan untuk memilih jawaban yang menurut mereka benar dan dapat memilih lebih dari satu. Tetapi, mahasiswa yang menjawab dengan benar berjumlah 6 orang dari keseluruhan 43 orang.

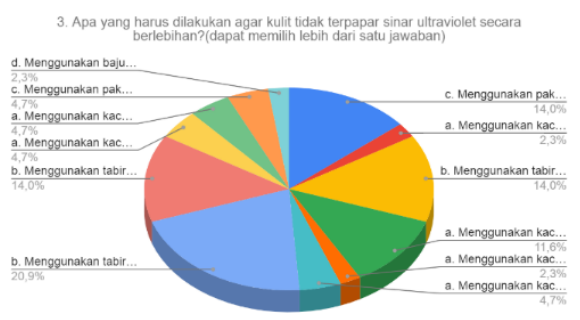

Gambar 3. Persebaran jawaban soal ketiga.

Pada soal nomor empat jawaban benar terdapat pada pilihan A, C, dan D. Terlihat pada grafik batang mahasiswa yang menjawab benar dari pilihan tersebut, 27 orang memilih A, 33 orang memilih C, dan 20 orang memilih D karena ini merupakan soal analisis jadi mahasiswa memilih jawaban menurut mereka yang paling benar, dan yang menjawab benar berjumlah 8 orang dari keseluruhan 43 orang.

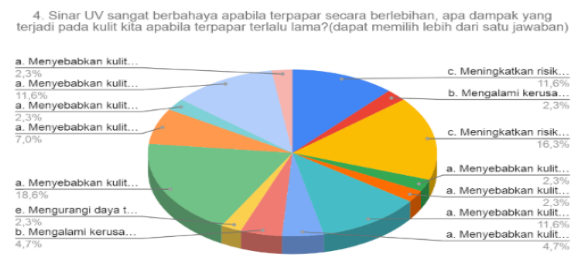

Gambar 4. Persebaran jawaban soal keempat.

Pada soal nomor lima jawaban benar terdapat pada pilihan B. Terlihat pada grafik batang mahasiswa yang menjawab benar dari pilihan tersebut sebanyak, 20 orang memilih B dari keseluruhan mahasiswa 43 orang, terhitung lumayan banyak mahasiswa yang dapat menjawab dengan benar.

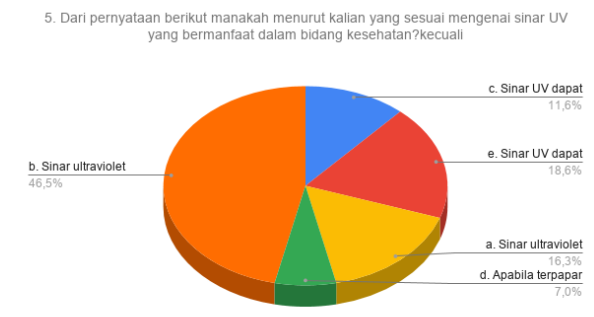

Gambar 5. Persebaran jawaban soal kelima. 
Pada soal nomor enam jawaban benar terdapat pada pilihan C. Soal ini berisikan perintah untuk mengurutkan langkah langkah, terlihat pada grafik batang mahasiswa yang menjawab benar dari pilihan tersebut sebanyak, 25 orang memilih $\mathrm{C}$ pada soal ini banyak dari responden yang menjawab benar.

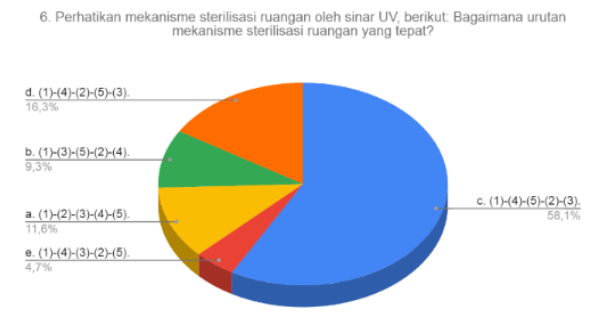

Gambar 6. Persebaran jawaban soal keenam.

Kemudian berikut merupakan grafik tabung dari jumlah keseluruhan soal yang terjawab benar oleh mahasiswa pendidikan fisika, pada grafik tabung tersebut terlihat jumlah mahasiswa yang menjawab benar per soal.

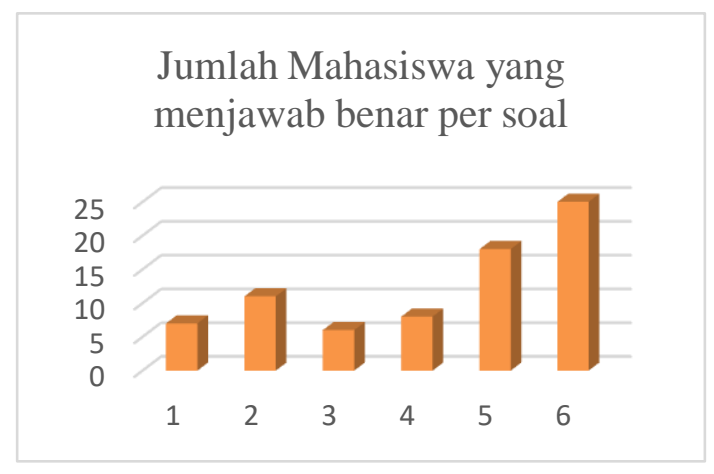

Gambar 6. Jumlah mahasiswa yang menjawab benar per soal

Terlihat pada grafik bahwa pada soal nomor 6, banyak dari mahasiswa dapat menjawab dengan benar dengan presentase $25 \%$, kemudian pada soal nomor 5 dengan presentase $18 \%$, soal nomor 4 presentase $8 \%$, soal nomor 3 presentase $6 \%$, soal nomor 2 presentase $11 \%$ dan pada soal nomor 1 presentase 7\%. Di tinjau dari soal tersebut pada nomor soal 6, 5 dan 2 banyak dari mahasiswa yang menjawab dengan benar.

Kemudian dilihat rata rata hasil dari keseluruhan mahasiswa pendidikan fisika dalam menjawab ke enam soal tersebut, hasil yang didapatkan yaitu sekitar 32,6\% dari keseluruhan mahasiswa pendidikan fisika yang berjumlah 43 orang menjawab dengan benar. Dapat disimpulkan dari hasil keseluruhan atau rata rata nilai dari mahasiswa pendidikan fisika, masih termasuk pada kategori kurang baik atau kemampuan dalam berpikir kritis mengenai 
pemanfaatan teknologi sinar ultraviolet pada bidang kesehatan masih kurang baik. Hasil ini sama dengan hasil penelitian Putra \& Sudarti (2015) yang menunjukkan bahwa rata-rata kemampuan berpikir kritis mahasiswa pada nilai 37 dan hasil penelitian Pradana, Parno, \& Handayanto (2016) yang menunjukkan bahwa rata-rata kemampuan berpikir kritis mahasiswa fisika adalah 24,29. Sejalan dengan penelitian tersebut, penelitian lain juga mendapatkan hasil nilai rata-rata kemampuan berpikir kritis calon guru fisika adalah 30 (Gunawan \& Liliasari, 2012). Ini semakin memperkuat bahwa kemampuan berpikir kritis pebelajar, termasuk mahasiswa di Indonesia masih kurang. Hal inilah yang menyebabkan mahasiswa Indonesia kurang bisa bersaing dalam dunia internasional (Frijters et al, 2008). Hal ini juga sejalan dengan pendapat Al-Kindi \& AlMekhlafi (2017). Terkadang mahasiswa belum terbiasa menyelesaikan soal pemecahan masalah, sedangkan proses pemecahan masalah menjadi salah satu tuntutan asesmen berpikir kritis (Thompson, 20011). Selain itu, mahasiswa tidak menggunakan kemampuan berpikir kritis untuk pemecahan masalah (Walker, 2003). Mahasiswa cenderung mempercayai dan menerima informasi yang diberikan soal tanpa mengevaluasi terlebih dahulu.

\section{SIMPULAN}

Kemampuan yang harus dimiliki oleh setiap orang yang belajar, yaitu adalah kemampuan bepikir kritis . Orang yang belajar butuh untuk dapat memahami, mengidentifikasi, menganalisis kemudian yang terakhir menyimpulkan apa yang mereka telah pelajari terutama salah satu orang yang belajar ini adalah mahasiswa, mahasiswa juga dituntut melakukan berpikir kritis agar hasil yang didapatkan dapat menjadi lebih baik. Kemudian setelah dilaksanakan penelitian terhadap mahasiswa pendidikan fisika, kemampuan berpikir kritis dari mahasiswa pendidikan fisika masih tergolong kurang baik, hanya dengan presentase $32,6 \%$ yang didapatkan setelah menjawab soal soal beraspek berpikir kritis.

\section{DAFTAR PUSTAKA}

Al-Kindi, Naeema Saleh \& AL-Mekhlafi, Abdo Mohammed.(2017). The Practice and Challenges of Implementing Critical Thinking Skills in Omani Post-basic EFL Classrooms.English Language Teaching; Vol. 10, No. 12.

Ariani, T., \& Yolanda, Y. (2019). Effectiveness of Physics Teaching Material Based on Contextual Static Fluid Material. Kasuari: Physics Education Journal (KPEJ), 2(2), 7081. 
Ennis, Robert H. (2013). The Nature of Critical Thinking: An Outline of Critical Thinking Dispositions and Abilities.http://criticalthinking.net/longde finition.html. Last revised, 2013. Original versionpresented at the Sixth International Conference on Thinking, Cambridge, MA, July, 1994. Most recently published version: (2011). Inquiry: Critical Thinking across the Disciplines, 26 (1), 4-18.

Facione. (2000). The Disposition toward Critical Thinking: Its Character, Measurement, and Relation to Critical Thinking Skill. Informal Logic, 20(1), 61-84.

Fakhriyah, F. (2014). Penerapan Problem Based Learning dalam Upaya Mengembangkan Kemampuan Berpikir Kritis Mahasiswa. Jurnal Pendidikan IPA Indonesia, 3(1).

Frijters, S., Dam, G., \& Rijlaarsdam, G. (2008). Effects of dialogic on valueloaded critical thinking. Learning and Instruction (Vol. 18). https://doi.org/10.1016/j.learninstruc .2006 .11 .001

Gunawan \& Liliasari. (2012). Model virtual laboratory fisika modern untuk meningkatkan disposisi berpikir kritis calon guru. Cakrawala Pendidikan, Vol. 2, pp. 185-199.

Harefa, D. P., \& Gumay, O. P. U. (2021). Pengembangan Buku Ajar Fisika Berbasis Problem Based Learning pada Materi Elastisitas dan Hukum Hooke. SILAMPARI JURNAL PENDIDIKAN ILMU FISIKA, 3(1), 1-14.

Lai, Emily R. (2011). Critical Thinking: A Literature Review. Pearson's Research Reports.

Putra, P. D. A. \& Sudarti. (2015). Pengembangan Sistem E-Learning untuk Meningkatkan Keterampilan Berpikir Kritis Mahasiswa. Jurnal Fisika Indonesia, Vol. 19, No. 55, pp. $45-48$.

Pradana, S. D. S., Parno, P., \& Handayanto, S. K. (2017). Pengembangan tes kemampuan berpikir kritis pada materi Optik Geometri untuk mahasiswa Fisika. Jurnal Penelitian dan Evaluasi Pendidikan, 21(1), 51-64.

Salsabillah, S., Sudarti., \& Supeno. (2018). Analisis Penguasaan Konsep-Konsep Fisika Pokok Bahasan Gelombang Elektromagnetik pada Siswa Kelas XII SMA. Seminar Nasional Pendidikan Fisika 2018 (pp 259). Universita Jember

Thompson. Claudette. (2011). Critical Thinking across the Curriculum: Process over Output. International Journal of Humanities and Social Science Vol. 1 No. 9 [Special Issue July 2011].

Walker, Stay E. (2003). Active Learning Strategies to Promote Critical Thinking. Journal of Athletic Training. 2003;38(3):263-267

Zakiya, Z., Amin, A., \& Lovisia, E. (2019). Penerapan Metode Eksperimen pada Pembelajaran Fisika Siswa Kelas X Sman 3 Lubuklinggau Tahun Pelajaran 2018/2019. Silampari Jurnal Pendidikan Ilmu Fisika, 1(2), 130-138. 